\title{
Sampling plans for aphids and their parasitoids in blueberry fields in Argentina
}

\author{
Margarita Rocca* and Nancy Mabel Greco \\ CEPAVE (CONICET-UNLP, CCT La Plata) Calle 2 \# 584 (1900) and Cátedra de Control Biológico, Facultad de Ciencias \\ Naturales y Museo, UNLP, La Plata, Argentina
}

(Received 5 October 2011; final version received 20 June 2012)

\begin{abstract}
Densities of aphids (Aphis gossypii and A. spiraecola) and mummified aphids at different phenological stages of a blueberry crop were estimated for the purpose of developing sampling plans. Our data set comprised 99 samples taken during the period 2006-2008 in four fields in Buenos Aires Province, Argentina. Estimation of population density based on the proportion of sample units infested by individuals was investigated. We also calculated the minimum number of sample units to estimate the density of individuals on buds and buds + flowers using enumerative sampling. The relative precision of both methods was compared. Moreover, an enumerative sequential sampling protocol was developed. The presence-absence sampling plan gave density estimates with large variances (as measured by confidence intervals and large standard errors). The aggregation of mummies was similar on buds and buds + flowers, so the required number of sample units for density estimates was the same. Relative precision of estimates was much lower for the presence-absence sampling than the enumerative sampling, even at intermediate densities. An enumerative sequential plan would be the most appropriate and useful method in management plans for aphids and mummified aphids in blueberries.
\end{abstract}

Keywords: Aphis gossypii; Aphis spiraecola; enumerative sampling plan; mummified aphids; presence-absence sampling plan; Vaccinium corymbosum

\section{Introduction}

Aphids affect a wide variety of crop plants such as citrus, tobacco, alfalfa, cereals, cotton and beans, and also orchard crops, in various parts of the world (Blackman and Eastop 2000; Delfino 2004; Kavallieratos et al. 2002, 2007; Imwinkelried et al. 2004; Tomanović et al. 2009). They support complexes of parasitoid wasps (Braconidae, Aphelinidae) (Berta et al. 2002; Kavallieratos et al. 2005a, 2010), which can also be attacked by other parasitoids (secondary parasitoids or hyperparasitoids).

Blueberries (Vaccinium corymbosum L.) are traditionally grown in the northern Hemisphere, but there are also productive areas in Australia, New Zealand, Chile and Argentina. In blueberry fields in the USA, Illinoia pepperi (MacGillivray) (Hemiptera: Aphididae) is the aphid species that is considered to be a sporadic pest and can reach high densities (Isaacs et al. 2008). In Chile, Aphis gossypii Glover, Macrosiphum euphorbiae (Thomas) and Myzus persicae (Sulzer) (Hemiptera: Aphididae) are occasional pests of blueberries (Larraín et al. 2007). In blueberry fields in Argentina, A. gossypii Glover and A. spiraecola Patch are the most common aphid species (Rocca and Greco 2011). These two species are closely related and morphologically similar (Vanlerbergue-Masutti and Chavigny 1998). In Argentina, A. gossypii is reported to be a pest of strawberries, lemons, apples, oranges, pears, tangerines and sweet peppers, and $A$. spiraecola is reported to be a pest of apples and pears (SINAVIMO 2012). Aphis gossypii is an important vector of the cotton leafroll dwarf virus (CLRDV) (known as "blue disease") and the citrus tristeza virus (CTV), but in blueberries there has been no record of damage by viruses until now. These aphid species often reach high densities; however, the economic threshold levels have not yet been ascertained.

Broad-spectrum insecticides are applied to blueberries in Argentina when growers consider that aphid density is high, albeit that they lack the tools to estimate the density of aphids accurately. On the other hand, to know parasitoid density is useful to minimize adverse effects of pesticides on natural enemy populations, because applications could be avoided if parasitoid density were high. Such knowledge may lead to more accurate management decisions aimed at controlling aphids in blueberries (Kavallieratos et al. 2005b). Estimating the population density from presence-absence sampling plans appears to be an effective alternative to the counting method (enumerative sampling), given the small size and the high numbers of individuals on plants (Nachman 1984; Binns and Nyrop 1992). However, presence-absence sampling requires more samples than enumerative sampling in order to estimate densities with the same level of precision. 
In this paper we report the development of a presence-absence sampling plan to estimate the density of aphids ( $A$. gossypii and $A$. spiraecola) and a presence-absence sampling plan to obtain an estimate of the density of mummified aphids at different phenological stages of blueberries in Argentina. (Mummified aphids contain the pupal or adult stages of parasitoid wasps that have previously developed inside the living aphid, as larvae.) We also calculate the minimum number of samples to assess the density of aphids and mummified aphids by enumerative sampling and by sequential sampling with a fixed precision level.

\section{Materials and methods}

The study was conducted from June/July of 2006 to December of 2008 in four commercial blueberry fields, approximately 4 ha each, located in different sites of the province of Buenos Aires (Argentina). The four fields selected were Gobernador Castro (S33 $38^{\prime} 9.7^{\prime \prime}$, W59 $\left.51^{\prime} 6.4^{\prime \prime}\right)$, San Pedro (S33 $42^{\prime} 6.9^{\prime \prime}$, W59 51 $\left.8.9^{\prime \prime}\right)$,

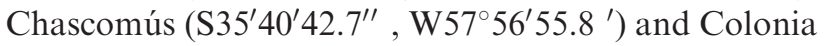

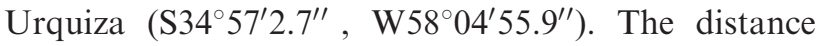
between them ranged between $10 \mathrm{~km}$ and $286 \mathrm{~km}$. An anti-hail mesh was installed in the first two fields.

A random sampling design was used. Samples were taken monthly covering all blueberry phenological stages (Rivadeneira and Bouvet 2007). Each sample consisted of 60 sample units conformed by two subsampling units (three vegetative buds and three bunches of flowers), depending on the resources available to aphids in each phenological stage of the plant (Table 1). To determine the optimum number of sub-sample units per sample unit $(n)$, the variance of within-plant sub-samples must be compared with the variance of the between-plant sub-samples and set against the effort of sampling within the same plant or of moving to another plant and sampling within it. If the interplant variance is the major source of overall variance, and unless the cost of moving from plant to plant is very high, $n$ will be of the order of 1 or less (which means 1 in practice) (Southwood 1978). The dispersion of aphids is aggregated at both field and plant scales (Way and Cammell 1970), so both of these sources of variance will be important. Moreover, given that sampling in the same plant consumes less time than moving to another randomly selected plant, we decided to take three vegetative buds and three bunches of flowers (hereinafter called "flowers") per plant instead of taking one vegetative bud and one bunch of flowers per plant. Sub-sample units were sealed separately in plastic bags for each sample unit and were transported to the laboratory in portable refrigerators.

All sample units were reviewed under a stereoscopic microscope and the number of aphids per plant structure was recorded. Both $A$. gossypii and $A$. spiraecola cause similar damage and are found together on the same plant parts (Rocca 2010). These species are morphologically similar, so it is very difficult to distinguish between them with the naked eye. In order to devise useful sampling guidelines for growers, we decided to perform the analysis without distinguishing the species.

All mummified aphids per sub-sample unit were placed in Petri dishes, which were covered with plastic film until emergence of parasitoids or hyperparasitoids. All aphids per sub-sample unit were also placed in Petri dishes covered with plastic film during 2 days to verify parasitism. For the analysis of parasitism, mummified aphids at the time of sampling and those appearing two days afterwards were considered. The percentage of mummified aphids was calculated as: (number of mummified aphids per sub-sample unit/number of aphids + number of mummified aphids per sub-sample unit) $* 100$. The percentage of hyperparasitized mummified aphids was calculated as: (number of hyperparasitoids per sub-sample units/number of aphids + number of mummified aphids per sub-sample unit) *100 (Kavallieratos et al. 2005a).

In total, 122 samples (field/date data sets) were collected for aphids and mummified aphids. Of these, 99 had mean densities higher than zero individuals per sample unit and were used to develop the sampling plans.

Considering the phenological stages shown in Table 1 , when the crop is at V2, V3, V1-R1 and R4 the plants have vegetative buds, and when the crop is at V1-R2, $\mathrm{R} 3$ and R4 the plants have vegetative buds and flowers; therefore, different sampling schemes in each case were required. Samples were pooled according to the

Table 1. Phenological stages of blueberry crops in Buenos Aires province, Argentina: months that each stage involves and resources available to aphids.

\begin{tabular}{llll}
\hline & \multicolumn{1}{c}{ Phenological stages } & \multicolumn{1}{c}{ Month } & \multicolumn{1}{c}{ Resources } \\
\hline V2 & Summer budding & Jan-Feb-Mar & Vegetative buds \\
V3 & Dormancy and presence of senescent leaves & Apr-May & Relict vegetative buds \\
V1-R1 & Budding starts, spring budding and flower bud formation & June-July & Occasionally vegetative buds \\
V1-R2 & Spring budding and flowering starts & Aug-Sep & Vegetative buds, flowers \\
R3 & Open flower, fruit formation, unripened fruit & Oct & Vegetative buds, flowers \\
R4 & Ripe fruit & Nov-Dec & Vegetative buds, relict flowers \\
\hline
\end{tabular}

Source: Adapted from Rivadeneira and Bouvet (2007). 
phenological stage. In 35 samples, the sample unit for aphids was conformed by vegetative buds, while in 30 samples it was conformed by vegetative buds plus flowers. For mummified aphids, in 11 samples the sample unit consisted of vegetative buds whereas in 22 samples it consisted of vegetative buds plus flowers.

\subsection{Presence-absence sampling plans for aphids and mummified aphids}

For each sample, aphid density (expressed as the average number of aphids per sample unit), and the proportion of sample units with aphids were calculated. The same procedure was performed to develop presence-absence sampling plans for mummified aphids.

A distribution-free equation to describe the relationship between the density $(\mu)$ and the proportion of sample units with individuals $(1-p)$ (Gerrard and Chiang 1970) was used:

$$
\ln (\mu)=\alpha+\beta \ln (-\ln (1-p)),
$$

where $\alpha$ and $\beta$ are coefficients estimated by simple linear regression (SLR) and $p$ is the proportion of sample units without individuals.

Four regression analyses on the data were performed: (1) aphids on vegetative buds, (2) aphids on vegetative buds + flowers, (3) mummified aphids on vegetative buds and (4) mummified aphids on vegetative buds + flowers.

The population densities $(\hat{\mu})$ in each case were therefore estimated by:

$$
\hat{\mu}=\exp (\hat{\alpha}+\hat{\beta} \ln (-\ln (1-p))),
$$

We estimated the variance of the estimated density logarithm using the term suggested by Schaalje et al. (1991):

$$
v_{s}=c 1+c 2+(c 4-c 3)
$$

where

$$
\begin{gathered}
c 1=\left[\hat{\beta}^{2}(1-(1-p))\right] /\left[n(1-p)(\ln (1-p))^{2}\right] \\
c 2=\operatorname{MSE}\left\{1 / N+[\ln (-\ln (1-p))-\bar{p}]^{2} / S S P\right\} \\
c 3=\exp \{\hat{a}+(\hat{b}-2)[\hat{\alpha}+\hat{\beta} \ln (-\ln (1-p))]\} / n \\
c 4=M S E,
\end{gathered}
$$

and $n$ is the number of unit samples, $N$ is the number of samples used to fit the regression equation, MSE is the residual mean squared error from the $\operatorname{SLR}$ of $\ln (\mu)$ on $\ln (-\ln (1-p)), \bar{p}$ is the mean value of $\ln (-\ln (1-p))$ for the samples used in the regression, SSP is the sum of squared deviations of the $\ln (-\ln (1-p))$ values from $\bar{p}$, and $\hat{a}$ and $\hat{b}$ are SLR estimates of parameters of the Taylor (1961) mean-variance $\left(\sigma^{2}\right)$ relationship:

$$
\ln \left(\sigma^{2}\right)=a+b \ln (\mu) .
$$

The confidence intervals to $\ln (\hat{\mu})$ are:

$$
\left[\ln (\hat{\mu})-t_{N-2,1-\alpha / 2} \sqrt{v_{s}}, \ln (\hat{\mu})+t_{N-2,1-\alpha / 2} \sqrt{v_{s}}\right] .
$$

In this expression $\ln (\hat{\mu})$ stands for the prediction based on the regression (1) and $t_{N-2,1-\alpha / 2}$ is the $1-\alpha / 2$ quantile of Student's $t$-distribution with $N-2$ degrees of freedom. By applying the exponential function we obtained $90 \%$ confidence intervals for $\hat{\mu}$ from $v_{\mathrm{s}}$ estimated for 60 sample units.

\subsection{Enumerative sampling plan for aphids and mummified aphids}

This procedure consists in determining an appropriate number of sample units from the field to estimate the density with a desired level of precision. For the estimation of minimum sample size for a given density and a given level of precision, represented by the proportion of standard error of the mean $(D)$, the formula provided by Finch et al. (1975) was used:

$$
n=a x^{(b-2)} / D^{2}
$$

where $a$ and $b$ are Taylor's estimates and $x$ is the mean. Taylor' parameters obtained for aphids on vegetative buds and aphids on vegetative buds + flowers were compared by the $t$-test. The same was done for mummified aphids. When slopes and intercepts were not significantly different, the entire data set was used to develop a sampling plan that included vegetative buds and vegetative buds + flowers. This relation was examined for $D=0.1,0.2$ and 0.3 , the highest precision level being 0.1 , which corresponded to the lowest proportion of standard error of the mean.

We analyzed the relative precision of estimates based upon enumerative and presence-absence plans, expressed in terms of the coefficient of variation or relative precision (Nachman 1984). For the enumerative sampling plan it is:

$$
C_{(x)}=\frac{\sqrt{\operatorname{var}(x)}}{x}=\sqrt{a / n} x^{(b-2) / 2} .
$$

Whereas, the coefficient of variation associated with the binomial sampling plan is:

$$
C_{(\hat{\mu})} \cong \sqrt{v_{s}(\ln \hat{\mu})}
$$

\subsection{Enumerative sequential sampling plan}

To construct stop-lines for fixed-precision levels of a sequential sampling plan the following formula from Green (1970), based on Taylor's power law, was used: 


$$
T_{n}=\left(\frac{a n^{(1-b)}}{D^{2}}\right)^{1 /(2-b)},
$$

where $T_{n}$ is the cumulative total of individuals for the sample units, $a$ and $b$ are Taylor's estimates, and $D$ is the precision level.

Sample units are taken and individuals are counted, then if the point $\left(n_{i}, T_{n i}\right)$ is below the line for the required precision level it is necessary to continue the sampling because the predetermined level of precision has not been achieved. When the point $\left(n_{i}, T_{n i}\right)$ is above the boundary line for the desired level of precision the density can be estimated as $T_{n i} / n_{i}$ at the desired level of precision.

\section{Results}

The density of aphids per sample unit ranged from 0.02 to 15 individuals per three vegetative buds and 0.05 to 30 individuals per three vegetative buds + three flowers. The density of mummified aphids ranged from 0.03 to 0.6 and 0.02 to 8 per three vegetative buds and three vegetative buds + three flowers, respectively.

The parasitoid complex of $A$. gossypii and $A$. spiraecola in blueberry fields in Argentina was composed of Aphidius colemani Viereck, Aphidius ervi Haliday, Lysiphlebus testaceipes (Cresson), Diaeretiella rapae (McIntosh) (Hymenoptera: Braconidae) and Aphelinus sp. (Hymenoptera: Aphelinidae). The percentages of parasitism were variable and ranged between $0.4 \%$ and $100 \%$. Aphidius colemani and L. testaceipes were the most abundant parasitoids with a mean relative abundance of $66 \%$ and $23 \%$, respectively. Hyperparasitoids, namely Pachyneuron sp., Asaphes sp. (Hymenoptera: Pteromalidae), Dendrocerus carpenteri (Curtis) (Hymenoptera: Megaspilidae) and Syrphophagus sp. (Hymenoptera: Encyrtidae), were also found in all fields, causing up to $40 \%$ of hyperparasitism.

\subsection{Presence-absence sampling plans for aphids and mummified aphids}

Estimation of the intercept and the slope by linear regression between the density $(\mu)$ and the proportion of sample units with aphids $(1-p)$ gave the values 2.87 and 1.27, respectively, for the vegetative bud sample units. For vegetative bud + flower sample units these were 3.24 and 1.43. The $R^{2}$ values obtained in the regression were 0.62 for buds and 0.68 for buds + flowers. Both regressions were significant at $P<0.001$. The intercept and the slope by linear regression between the density and the proportion of sample units with mummified aphids were 0.85 and 1.02 , respectively, for vegetative buds sample units and 1.97 and 1.26 for vegetative bud + flower sample units. The $R^{2}$ values obtained in the regression were 0.68 and 0.79 . Both regressions were significant at $P<0.001$. The relationship between densities and proportion of sample units with individuals at $90 \%$ confidence interval is shown in Figure 1a-d.

\subsection{Enumerative sampling plan for aphids and mummified aphids}

Taylor's parameters (Table 2) were significantly different in respect of buds or buds + flowers as sample units for aphids (intercept: $t=5.65 ; \mathrm{df}=32$; $P=<0.05$; slope: $t=2.36 ; \mathrm{df}=61 ; P=<0.05$ ), but they were not significantly different to mummified aphids (intercept: $t=1.30 ; \mathrm{df}=30 ; P=>0.05$; slope: $t=0.45 ; \quad \mathrm{df}=29 ; P=>0.05)$. So, enumerative and sequential enumerative sampling plans for mummified aphids were developed with all of the data set $(N=33)$. As the density of aphids and mummified aphids increased, minimum sample size required for a specified precision level decreased (Figure 2a-c).

The minimum number of sample units required under low density scenarios, for example, 5 aphids per sample unit, was $>1000, \approx 310$ and $\approx 136$ for precision levels of $0.1,0.2$ and 0.3 , respectively (Figure 2a). For buds + flowers it was $\approx 980, \approx 245$ and $\approx 110$ for precision levels of $0.1,0.2$ and 0.3 , respectively (Figure $2 b$ ). As the mean density of aphids increased to 30 aphids per sample unit, minimum sample size decreased $(\approx 705, \approx 175$ and $\approx 78$ for vegetative buds at precision levels of $0.1,0.2$ and 0.3 respectively, and $\approx 575, \approx 145$ and $\approx 65$ for vegetative buds + flowers at the same precision levels) (Figure 2a-b). The sample size required to estimate the density of mummified aphids was lower than those for aphids. For 5 mummified aphids per sample unit, the sample size was $>500, \approx 150$ and $\approx 65$ at a precision level of $0.1,0.2$ and 0.3 , respectively (Figure 2c). As the mean density of mummified aphids increased to 30 , sample size decreased $(\approx 285, \approx 65$ and $\approx 30$ at a precision level of $0.1,0.2$ and 0.3 respectively).

Figure 3 shows the relative precision of estimates based upon both sampling plans. In the enumerative sampling plan, relative precision increased with increasing density, however the presence-absence sampling plan provided the most precise estimates for intermediate densities. Anyway, the relative precision was always higher for enumerative plan than presence-absence plan. For example, a density of 5 aphids per three vegetative buds would be estimated with a standard error of the density higher than $100 \%$, even taking a large number of sample units $(n=300)$. Instead, a significantly lower number of sample units $(n=100)$ would allow the estimation of the same density with a standard error of approx. $30 \%$ by enumerative sampling.

\subsection{Enumerative sequential sampling plan}

The stop lines constructed for a precision level $D=0.2$, corresponding to aphids on vegetative buds, aphids on vegetative buds + flowers and mummified aphids on vegetative buds + flowers, are shown in Figure 4. To 

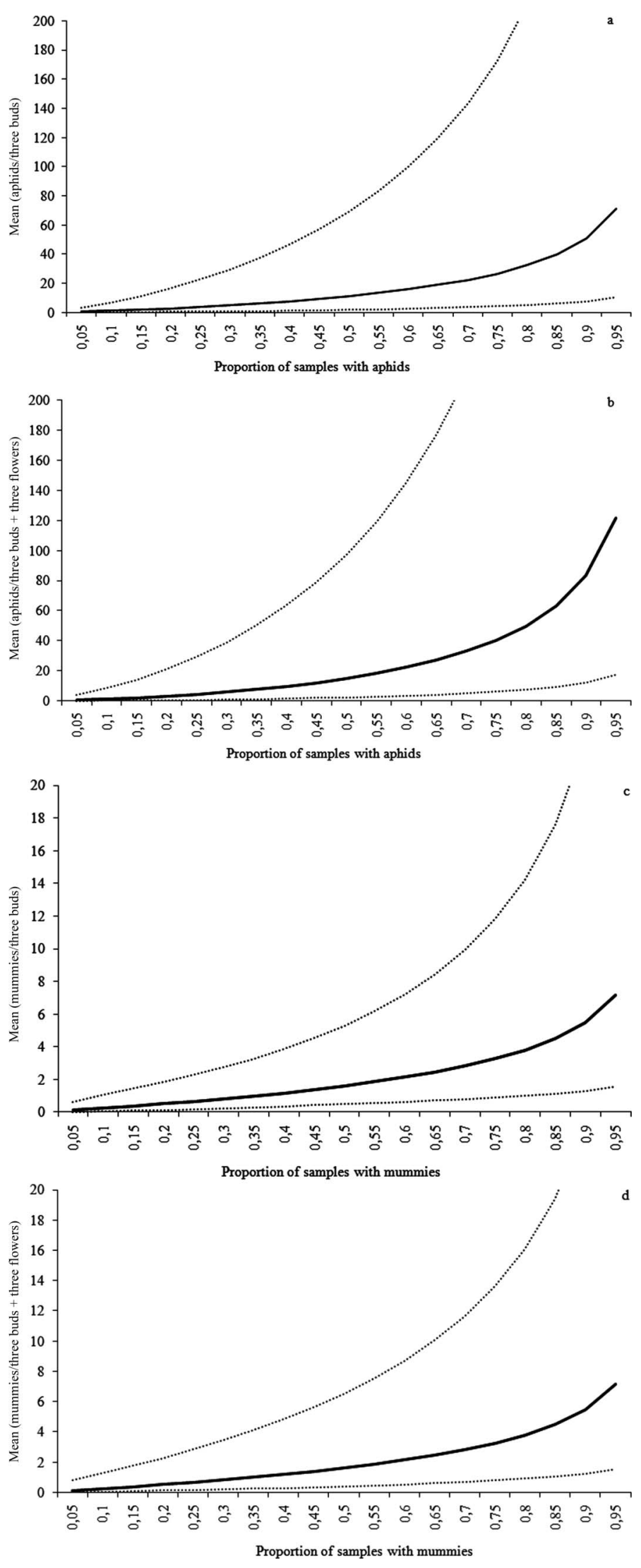

Figure 1. Relationship between the proportion of sample units with individuals and mean number of individuals per sample unit. a: Aphids per three vegetative buds, data were fitted to the equation $y=0.0551 \ln (x)+0.175\left(R^{2}=0.885\right)$; $\mathbf{b}$ : aphids per three vegetative buds + three bunches of flowers, data were fitted to equation $y=0.0844 \ln (x)+0.2007\left(R^{2}=0.941\right)$; c: mummified aphids per three vegetative buds, the data were fitted to equation $y=1.0238 \ln (x)+0.8519\left(R^{2}=0.679\right)$; d: mummified aphids per three vegetative buds + three bunches of flowers, the data were fitted to equation $y=1.2631$ $\ln (x)+1.9713\left(R^{2}=0.788\right)$. Broken lines denote $90 \%$ confidence intervals. 
Table 2. Taylor's parameters used for enumerative sampling plan for aphids and mummified aphids.

\begin{tabular}{lrccc}
\hline Aphids & $A^{1}$ & $a^{2}$ & $b^{3}$ & $R^{24}$ \\
\hline Vegetative buds & 20.37 & $1.31^{\mathrm{a} *}$ & $1.69^{\mathrm{a} * *}$ & 0.97 \\
Vegetative buds + flowers & 15.86 & $1.20^{\mathrm{b} *}$ & $1.70^{\mathrm{b} * *}$ & 0.96 \\
Mummified aphids & 7.12 & $0.85^{\mathrm{a} *}$ & $1.46^{\mathrm{a} * *}$ & 0.89 \\
Vegetative buds & 12.26 & $1.09^{\mathrm{a} *}$ & $1.60^{\mathrm{a} * *}$ & 0.95 \\
Vegetative buds + flowers & 11.25 & 1.05 & 1.60 & 0.94 \\
All data set & &
\end{tabular}

${ }^{1}$ Antilogarithm of $a ;{ }^{2} y$-intercept value for Taylor's model; ${ }^{3}$ slope value for Taylor's model; ${ }^{4}$ Correlation coefficient value for goodness-of-fit for Taylor's model; * $a$-values are significantly different from $0(\alpha=0.05) ; * * b$-values are significantly different from 1 $(\alpha=0.05)$. Values followed by the same letter within a column are not significantly different $(P<0.05)$. evaluate when the sampling would stop, convex lines that represent the expected cumulative number of individuals were calculated as $T_{n}=x n$ for densities of $x=5$ and $x=30$ individuals per sample unit. For example, at density of $x=5$ aphids per three vegetative buds the sampling would stop after taking 310 sample units, whereas the sampling would stop after 175 sample units at density of $x=30$ (Figure 4).

\section{Discussion}

In all sites sampled, aphids were recorded mainly on vegetative buds and flowers, as is the case in blueberry fields in the USA and Chile (Larraín et al. 2007; Isaacs
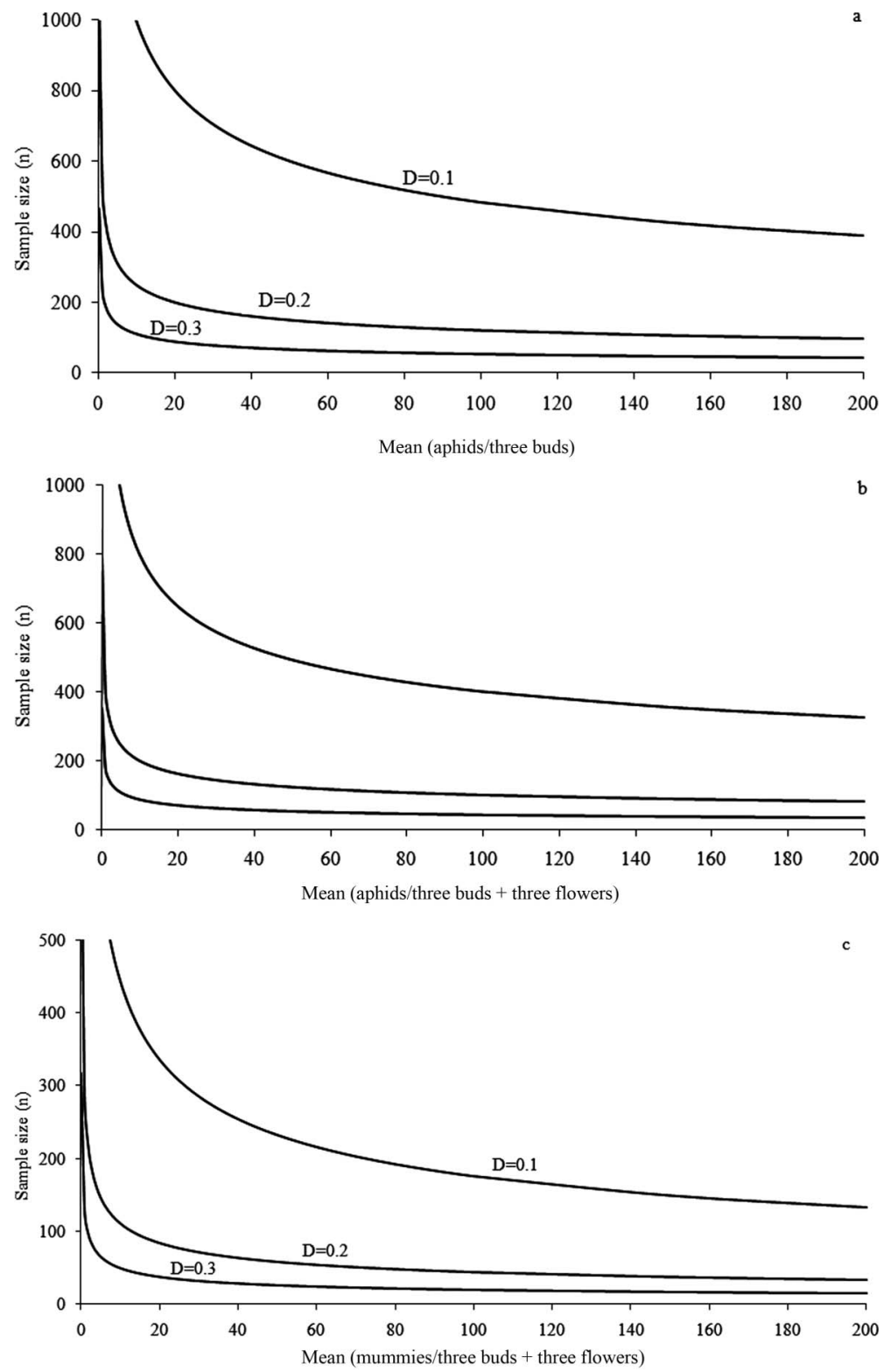

Figure 2. Sample size as a function of density, for various precision levels $(D=0.1, D=0.2$ and $D=0.3)$ in enumerative sampling plans. a: aphids per three vegetative buds, b: aphids per three vegetative buds + three bunches of flowers; $\mathbf{c}$ : mummified aphids per three vegetative buds + three bunches of flowers. 

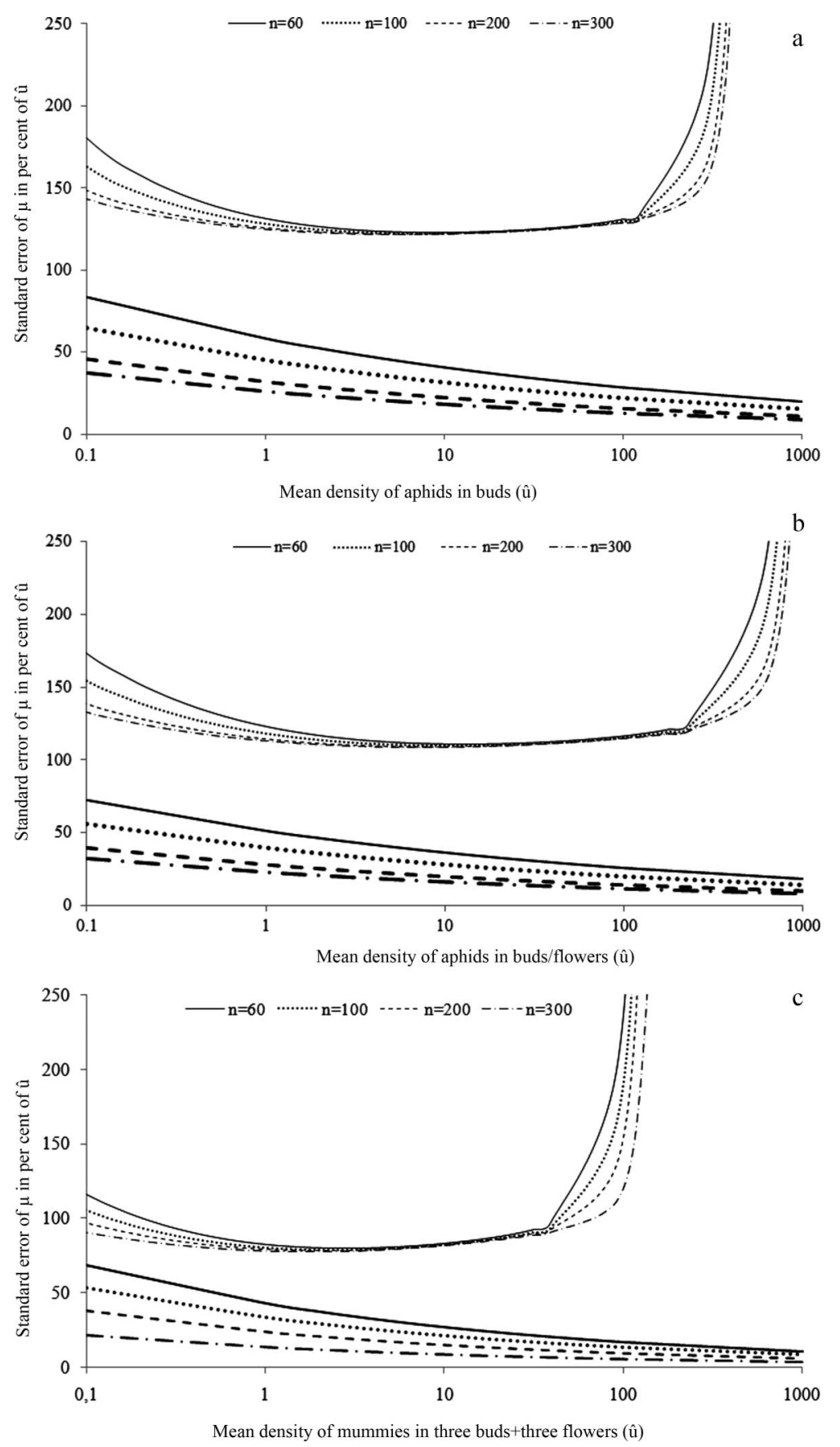

Figure 3. Standard error of density estimates expressed as percentage of the mean number of individuals per sample unit as a function of density for different sample sizes. Full lines: estimates based on the proportion of unit samples with individuals in a sample. Broken lines: estimates based on enumerative sampling. a: aphids per three vegetative buds; $\mathbf{b}$ : aphids per three vegetative buds + three bunches of flowers; c: mummified aphids per three vegetative buds + three bunches of flowers.

et al. 2008). The most abundant parasitoids were Aphidius colemani and Lysiphlebus testaceipes. Aphidius colemani is an Oriental species that has spread to South America, presumably accidentally (Starý 1975), and it is the most abundant parasitoid species in Argentina (Starý and Delfino 1986). The North American species L. testaceipes was introduced (and became established) in Argentina in 1984 for the purpose of controlling Schizaphis graminum (Rondani) (Hemiptera:
Aphididae) (Botto et al. 1991). Despite relatively high levels of hyperparasitism the parasitism was not disrupted during the study period.

Presence-absence and enumerative sampling plans have been developed for various aphids and their predators (Feng et al. 1993; Trumper and Gyenge 1998; Hodgson et al. 2004; Athanassiou et al. 2005), lepidopteran leafminers (Hamilton et al. 2004), whiteflies (Naranjo et al. 1996), mites (Nachman 1984; 


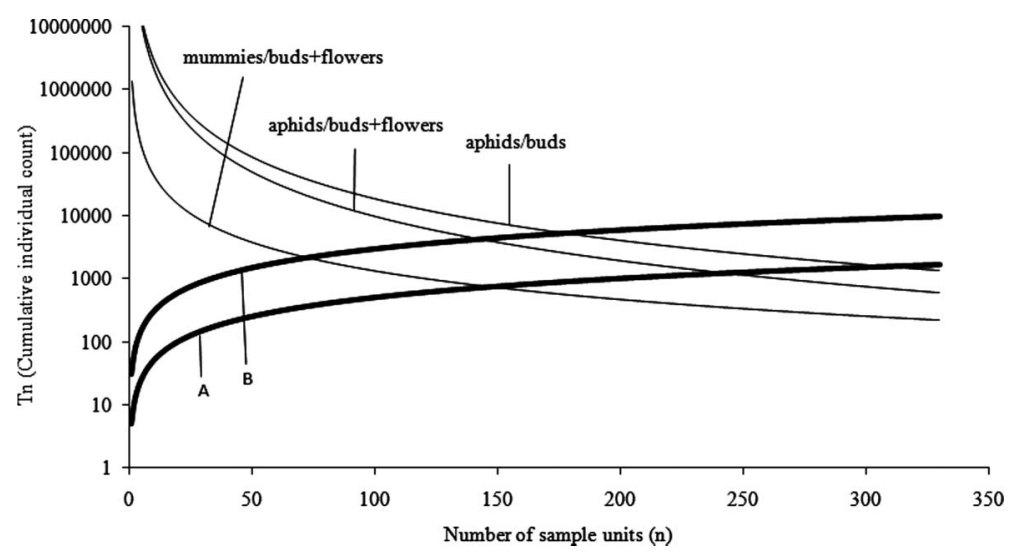

Figure 4. Comparison of Green's sequential sampling stop lines (concave curves) for estimating densities of aphids and mummified aphids with $D=0.2$. Convex curves A and B represent the expected cumulative number of individuals for densities of 5 and 30 individuals/sample units, respectively. Intersections of convex lines A and B with stop lines represent the number of sample units required.

Greco et al. 2004), thrips and their predators (Deligeorgidis et al. 2002), among others. Sampling plans for estimating parasitized aphid densities are very important in order to evaluate the mortality caused by parasitoids; however, sampling plans for estimating mummified aphids' density are not very common (Giles et al. 2003).

Counting all aphids or mummified aphids on each sample unit is time-consuming; sampling can be made easier and less time-consuming by substituting binomial counts (presence-absence) for complete counts (Binns and Nyrop 1992). For both aphids and mummified aphids the presence-absence sampling plan gave density estimates with large confidence intervals and large standard errors (>100\%). Generally, a level of $20 \%$ can be considered as an acceptable precision level in pest management (Southwood 1978). On the other hand, in enumerative sampling, high variation in the number of individuals among sample units may lead to an exponential increase in the sample size required for sufficient precision (Kapatos et al. 1996). The number of sample units required to estimate density, at different densities of aphids, was greater on vegetative buds than on vegetative buds + flowers. This is consistent with stronger aggregation of aphids on buds. Moreover, estimation of aphid density on vegetative buds would require a greater number of sample units, due to the fact that these insects were less abundant on vegetative buds than on flowers, as was observed also by Isaacs et al. (2008). Sampling of mummified aphids would require the same minimum number of sample units when the plant has only vegetative buds or vegetative buds + flowers, because they show similar spatial patterns.

Nachman (1984) proposed the combination of presence-absence and enumerative sampling plans to estimate densities of Tetranychus urticae and Phytoseiulus persimilis Owing to increasing the sample size used for the presence-absence method equal reliability may be attained. He found that the optimum sampling strategy was to use the enumerative plan at low densities, but to switch to the presence-absence plan at intermediate densities. In our case, we found that the relative precision was much lower for the presenceabsence sampling than for the enumerative sampling, even at intermediate densities, so the latter would be the more appropriate method at any density. The same occurred for mummified aphids, but slightly smaller standard errors of estimates were found. However, besides it being necessary to count all individuals, the enumerative sampling plan requires a preliminary estimation of density at each sampling date to estimate the sample size. The advantage of using an enumerative sequential sampling plan is that the number of sample units required to estimate the density is not fixed in advance. It allows one to stop sampling when the number of sample units is enough to estimate the density with a representative fixed-precision level (standard error to mean ratio of 0.20 ). This method appears to be the most appropriate and useful in management plans for aphids on blueberries.

The evaluation of the expected performance of a sampling plan in the field is the final step before it can be widely adopted by decision-makers and researchers as a reliable tool in integrated pest management strategies (Trumper and Gyenge 1998). In this case, such a decision should also be based on the knowledge of economic threshold levels and optimal host-parasitoid relationship to control aphids in blueberry fields (Giles et al. 2003).

\section{Acknowledgments}

We thank blueberry growers for permission to carry out the field work in their fields and Dr J.J. Martínez for the identification of parasitoids and hyperparasitoids. The authors want to thank the relevant suggestions made by the reviewers 
to improve this manuscript. This research was supported by grants from PICT 14331 Project and UBACyT G072.

\section{References}

Athanassiou CG, Kavallieratos NG, Tomanović Ž, Tomnović S, Milutinović M. 2005. Development of a sampling plan for Myzus persicae (Hemiptera: Aphidoidae) and its predator Macrolophus costalis (Hemiptera: Miridae) on tobacco. Eur J Entomol. 102:399-405.

Berta DC, Colomo MV, Ovruski NE. 2002. Interrelaciones entre los áfidos colonizadores del tomate y sus himenópteros parasitoides en Tucumán (Argentina). Bol San Veg Plagas. 28:67-77.

Binns MR, Nyrop JP. 1992. Sampling insect populations for the purpose of IPM decision making. Annu Rev Entomol. 37:427-453.

Blackman RL, Eastop VF. 2000. Aphids on the world's crops. An identification and information guide. 2nd edition. Chichester (England): John Wiley \& Sons.

Botto EN, Monetti NC, Saluso AR. 1991. Introduction, colonization and establishment of Lysiphlebus testaceipes (Hymenoptera: Aphidiidae), in Argentina. Entomophaga. 36:323-324.

Deligeorgidis PN, Athanassiou CG, Kavallieratos NG. 2002. Seasonal abundance, spatial distribution and sampling indices for thrip populations on cotton; a four year survey from central Greece. J Appl Entomol. 126:343348.

Delfino MA. 2004. Aphididae. In: Cordo HA, Logarzo G, Braun K, Di Iorio O, editors. Catálogo de insectos fitófagos de la Argentina y sus plantas asociadas. Buenos Aires (Argentina): Sociedad Entomológica Argentina Ediciones. p. 287-328.

Feng MG, Nowierski RM, Zeng Z. 1993. Binomial sampling plans for the English grain aphid, Sitobion avenae (Homoptera: Aphididae) based on an empirical relationship between mean density and proportion of tillers with different tally thresholds of aphids. Bull Entomol Res. 83:187-196.

Finch S, Skinner G, Freeman GH. 1975. The distribution and analysis of cabbage root fly egg populations. Ann Appl Biol. 79:1-18.

Gerrard DJ, Chiang HC. 1970. Density estimation of corn rootworm egg populations based upon frequency of occurrence. Ecology. 51:237-245.

Giles KL, Jones DB, Royer TA, Elliott NC, Kindler SD. 2003. Development of a sampling plan in winter wheat that estimates cereal aphid parasitism levels and predicts population suppression. J Econ Entomol. 96:975-982.

Greco NM, Tetzlaff GT, Liljesthröm GG. 2004. Presenceabsence sampling for Tetranychus urticae and its predator Neoseiulus californicus (Acari: Tetranychidae, Phytoseiidae) on strawberries in La Plata, Argentina. Int J Pest Manage. 50:23-27.

Green RH. 1970. On fixed precision level sequential sampling. Res Popul Ecol. 12:249-251.

Hamilton AJ, Schellhorn NA, Endersby NM, Ridland PM, Ward SA. 2004. A dynamic binomial sequential sampling plan for Plutella xylostella (Lepidoptera: Plutellidae) on broccoli and cauliflower in Australia. J Econ Entomol. 97:127-135.

Hodgson EW, Burkness EC, Huthinson WD, Ragsdale DW. 2004. Enumerative and binomial sequential sampling plans for soybean aphid (Homoptera: Aphididae) in soybean. J Econ Entomol. 97:2127-2136.

Imwinkelried JM, Fava FD, Trumper EV. 2004. Pulgones que atacan al cultivo de trigo. Boletín $\mathrm{N}^{\circ} 7$. Ediciones Instituto Nacional de Tecnología Agropecuaria.
Isaacs R, Schilder A, Miles TM. 2008. Longstroth. Blueberry aphid and blueberry shoestring virus. Extension Bulletin E3050. Michigan State University. Available from: http://www.ipm.msu.edu/cat09fruit/E3050.pdf (accessed 3 November 2011).

Kapatos ET, Stratopoulou ET, Sahinoglou A, Tsitsipis JA, Lycouresis DP. 1996. Development of an optimum sampling plan for the population of aphis gossypii (Hom., Aphididae) on cotton in Greece. J Appl Entomol. 120:245-248.

Kavallieratos NG, Athanassiou CG, Stathas GJ, Tomanovic Z. 2002. Aphid parasitoid (Hymenoptera: Braconidae: Aphidiinae) on citrus: seasonal abundance, association with the species of host plan and sampling indices. Phytoparasitica 30:365-377.

Kavallieratos NG, Athanassiou CG, Tomanović Z, Sciarretta A, Trematerra P, Žikić V. 2005b. Seasonal occurrence, distribution and sampling indices for Myzus persicae (Hemiptera: Aphidoidea) and its parasitoids (Hymenoptera: Braconidae: Aphidiinae) on tobacco. Eur. J. Entomol. 102:459-468.

Kavallieratos NG, Tomanović Ž, Athanassiou CG, Starý P, Žikić V, Sarlis GP, Fasseas C. 2005a. Aphid parasitoids (Hymenoptera: Braconidae: Aphidiinae) infesting cotton, citrus, tobacco and cereal crops in southerneastern Europe: aphid-plant associations and keys. Can. Entomol. 137:516-531.

Kavallieratos NG, Tomanović Ž, Sarlis GP, Vayias BJ, Žikić V, Emmanouel NE. 2007. Aphids (Hemiptera: Aphidoidea) on cultivated and self-sown plants in Greece. Biologia 62:335-344.

Kavallieratos NG, Tomanović Ž, Starý P, Žikić V, Petrović Obradović O. 2010. Parasitoids (Hymenoptera: Braconidae: Aphidiinae) attacking aphids feeding on Solanaceae and Cucurbitaceae crops in southeastern Europe: aphidiine-aphid-plant associations and key. Ann Entomol Soc Am. 103:153-164.

Larraín PS, Salas CF, Graña FS. 2007. Plagas del arándano y generalidades de manejo. Chile: INIA Intihuasi. p. 16-20.

Nachman G. 1984. Estimates of mean population density and spatial distribution of Tetranychus urticae (Acarina: Tetranychidae) and Phytoseiulus persimilis (Acarina: Phytoseiidae) based upon the proportion of empty sampling units. J Appl Ecol. 21:903-913.

Naranjo SE, Flint HM, Hennebery TJ. 1996. Binomial sampling plans for estimating and classifying population density of adult Bemisia tabaci in cotton. Entomol Exp Appl. 80:343-353.

Rivadeneira F, Bouvet JP. 2007. Taller: "Observaciones fenológicas en arándano y su entomofauna asociada en la zona de Concordia". VIII Reunión Nacional de Productores de Arándanos y otros Berries. Entre Ríos, Argentina.

Rocca M. 2010. Diversidad de los artrópodos fitófagos del cultivo de arándano (Vaccinium corymbosum) en la Argentina. Atributos poblacionales y factores de mortalidad de las principales especies. [PhD thesis]. [La Plata, Buenos Aires]: National University of La Plata, Argentina.

Rocca M, Greco NM. 2011. Diversity of herbivorous communities in blueberry crops of different regions of Argentina. Environ Entomol. 40(2):247-259.

Schaalje GB, Butts RA, Lysyk TJ. 1991. Simulation studies of binomial sampling: a new variance estimator and density predictor, with special reference to the Russian wheat aphid (Homoptera: Aphididae). J Econ Entomol. 84:140-147.

SINAVIMO. 2012. Aphis gossypii. Aphis spiraecola. [Internet]. January 2010. Sistema Nacional de Vigilancia y Monitoreo de Plagas - SENASA;[cited 2012 Apr 20]. Available from: http://www.sinavimo.gov.ar. 
Southwood TRE. 1978. Ecological methods. With particular reference to the study of insect populations. 2nd edition. London: Chapman and Hall.

Starý P. 1975. Aphidius colemani Viereck: its taxonomy, distribution and host range (Hymenoptera: Braconidae). Acta Entomol Bohemoslov. 72:156-163.

Starý P, Delfino MA. 1986. Parasitoids (Hym., Aphidiidae) of aphids (Hom., Aphididae) in Tucumán, Argentina. Boll Lab Ent Agr Filippo. 43:41-50.

Taylor LR. 1961. Aggregation, variance and the mean. Nature 189:732-735.

Tomanović Ž, Kavallieratos NG, Starý P, Stanisavljević LŽ, Ćtković A, Stamenković S, Jovanović S, Athanassiou CG. 2009. Regional tritrophic relationship patterns of five aphid parasitoid species (Hymenoptera: Braconidae: Aphidiinae) in agroecosystem-dominated landscapes of southeastern Europe. J Econ Entomol. 102:836-854.
Trumper EV, Gyenge JE. 1998. Binomial sampling plans for the spotted alfalfa aphid, Therioaphis trifolii in Argentina. Int J Pest Manage. 44:235-238.

Vanlerberghe-Masutti F, Chavigny P. 1998. Host-based genetic differentiation in the aphid species Aphis gossypii Glover, evidenced from RAPD fingerprints. Mol Ecol. 7:905-914.

Way MJ, Cammell M. 1970. Aggregation behaviour in relation to food utilization by aphids. In: Watson A, editor. Animal populations in relation to their food resources. Oxford: Blackwell Scientific Publications. p. 229-247. 